\title{
Coupled Plasma Filtration Adsorption in Patients with a History of Kidney Transplantation: Report of Two Cases
}

\author{
Quirino Lai ${ }^{a}$ Verdiana Di Pietro ${ }^{a}$ Samuele lesaria Sofia Amabili ${ }^{b}$ \\ Linda De Luca $^{a}$ Katia Clemente ${ }^{a}$ Antonio Famulari ${ }^{a}$ Francesco Pisani ${ }^{a}$

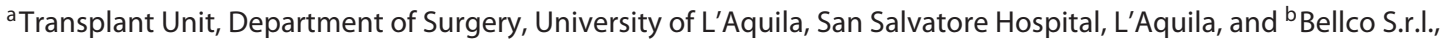 \\ Mirandola, Mo., Italy
}

\section{Key Words}

Rhabdomyolysis · Sepsis · Myoglobin · Cytokines · Graft survival

\begin{abstract}
Coupled plasma filtration adsorption (CPFA) is an extracorporeal treatment based on plasma filtration associated with an adsorbent cartridge and hemofiltration. CPFA is able to remove inflammatory mediators and it has been used to treat severe sepsis, septic shock and multiple organ dysfunction syndrome. Limited experience exists on the use of CPFA after solid organ transplantation. We report our experience with CPFA in 2 kidney transplant recipients with post-nephrolithotomy septic shock and severe unexplained rhabdomyolysis. In both the cases, excellent results were observed. In selected cases, CPFA can be safely and effectively used in patients with a solid organ transplant. However, additional studies are needed in this particular setting, to further investigate the potential role of CPFA for the treatment of other conditions associated with excessive inflammation, such as in rheumatologic disorders and delayed graft function.
\end{abstract}

(c) 2015 The Author(s)

Published by S. Karger AG, Basel

\section{Introduction}

Coupled plasma filtration adsorption (CPFA; Bellco S.r.l., Mirandola, Mo., Italy) is an extracorporeal treatment combining plasma filtration with an adsorbent cartridge and hemofiltration [1]. The main clinical application of CPFA is the treatment of sepsis [2-5]. The hydrophobic resins in the cartridge can absorb a wide range of pro-/anti-inflammatory mediators thus allowing the removal of the inflammatory mediators responsible for the development and maintenance of septic shock and multiple organ dysfunction syndrome. Other treatment modalities previously used to treat sepsis (drugs, monoclonal antibodies, other extracorporeal treatments) are mainly directed against a single substance or mediator. This high selective effect seems to represent their major limitation [6].

CPFA is likely to be a therapeutic option for severe rhabdomyolysis. In fact, the resin contained in the CPFA cartridge presents a highly adsorbing surface due to the great number of suitable pores that are capable of capturing molecules. The maximum of efficacy is obtained especially in case of substances with high-medium molecular weight, like myoglobin (about $18 \mathrm{kDa}$ ). On the other

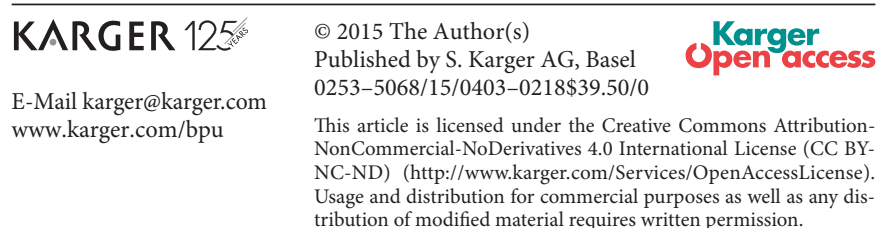

Dr. Quirino Lai, MD

Transplant Unit, Department of Surgery University of L'Aquila, San Salvatore Hospital

Via Vetoio 1, IT-67010 L'Aquila (Italy)

E-Mail lai.quirino@ libero.it 


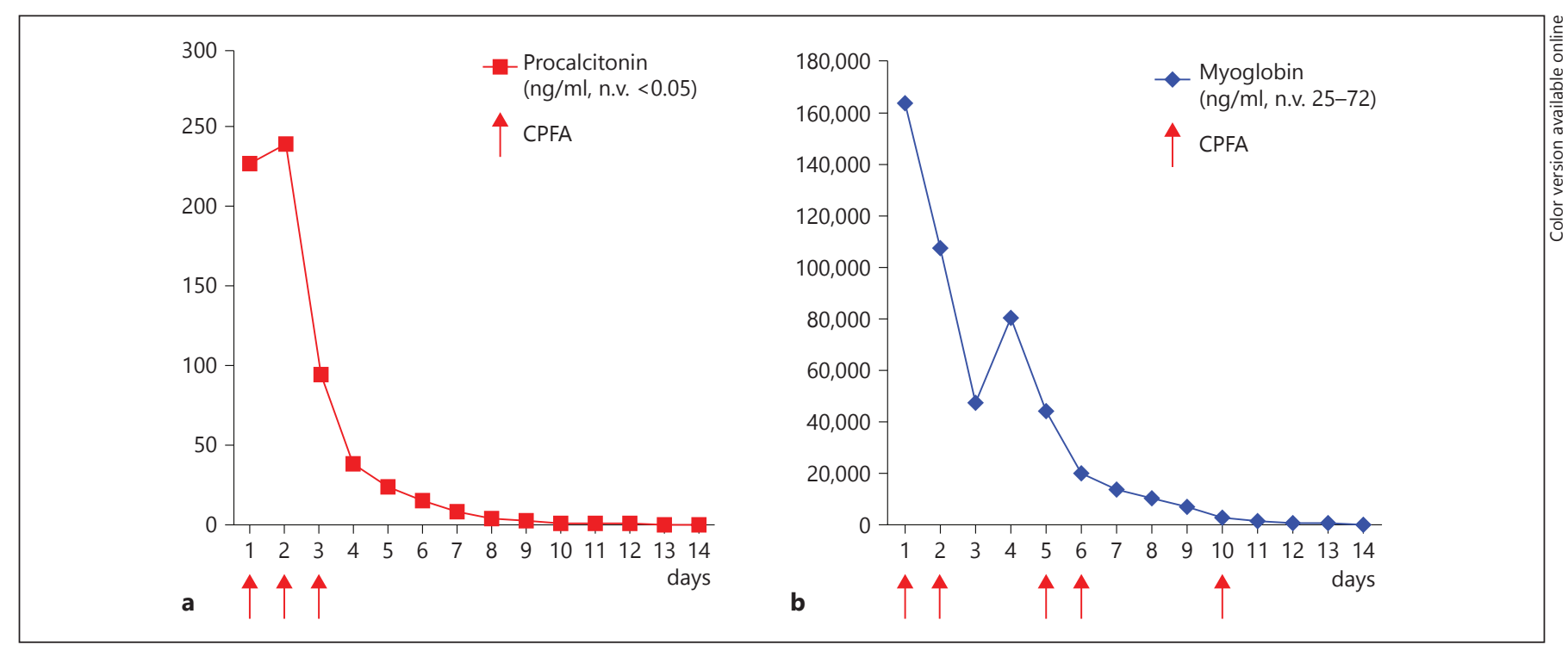

Fig. 1. a CPFA effect on serum procalcitonin levels in patient 1. b CPFA effect on serum myoglobin levels in patient 2.

hand, this molecule is typically not well removed by conventional dialysis filters [7].

Limited data exist on the use of CPFA in the setting of solid organ transplantation [8]. We herein report our experience with 2 patients who had a history of kidney transplantation.

\section{Case Report}

Case 1

A 64-year-old Caucasian man suffering from autosomal dominant polycystic kidney disease received his first deceased donor kidney transplant in May 2014. He was given extended-release tacrolimus, mycophenolate mofetil and steroids for immunosuppression. Past medical history included hypertension, T cell-mediated acute rejection and new-onset diabetes after transplantation. Three months after transplantation, the patient developed graft hydronephrosis due to an obstructing calculus in the renal pelvis. The stone was initially treated with extracorporeal shock wave lithotripsy and percutaneous nephrostomy placement. However, no significant improvement was observed. One month later, the patient was further hospitalized with a plan for surgical removal of the residual debris. At the time of surgery, serum creatinine $(\mathrm{sCr})$ was $2.52 \mathrm{mg} / \mathrm{dl}$, and systemic inflammation parameters were normal. Few hours after the procedure (percutaneous nephrolithotomy), the patient became pyrexial and hemodynamically unstable (blood pressure 70/40 $\mathrm{mm} \mathrm{Hg}$ ). Dopamine infusion of $15 \mu \mathrm{g} / \mathrm{kg} /$ min was started, with minimal improvement. Blood tests showed worsening graft function $(\mathrm{sCr} 4.81 \mathrm{mg} / \mathrm{dl})$ and significantly increased procalcitonin levels $(228 \mathrm{ng} / \mathrm{ml})$. The patient was immediately transferred to the intensive care unit with a diagnosis of septic shock. Immunosuppression was stopped except for intravenous (IV) administration of $20 \mathrm{mg}$ methylprednisolone daily. Antibi- otic therapy with $500 \mathrm{mg}$ IV meropenem administered 3 times a day and oral ciprofloxacin of $500 \mathrm{mg}$ daily was started. Three consecutive sessions of CPFA were also performed: continuous hemofiltration was given for $8 \mathrm{~h}$ during each treatment. Following treatment with CPFA, the patient's clinical condition rapidly improved with sustained normalization of blood pressure and procalcitonin (fig. 1a). After 4 days, the patient was stepped down but his graft function never recovered. To minimize the risk of recurrent infection and safely stop immunosuppression, we then decided to perform a graftectomy. The surgical procedure and the post-operative course were uneventful, and the patient was eventually discharged 8 days later. The clinical course is summarized in table 1 .

\section{Case 2}

A 65-year-old Caucasian woman suffering from autosomal dominant polycystic kidney disease received a deceased donor renal transplant in 1998. Past clinical history included dyslipidemia, cardiac hypertrophy, secondary hyperparathyroidism and nonvalvular atrial fibrillation. After 15 years of follow-up, she was still on a triple-agent immunosuppressive regimen (cyclosporine, mycophenolate mofetil and steroids), and her graft function was optimal (sCr nadir: $0.9 \mathrm{mg} / \mathrm{dl}$ ). During March 2014, the patient started complaining of malaise, severe asthenia, diffuse arthralgia and myalgia. Two weeks later, the patient was hospitalized with deteriorating general health condition. On admission, laboratory tests showed an acute kidney failure and severe rhabdomyolysis (zenith of serum myoglobin: 163,630 $\mathrm{ng} / \mathrm{ml}$ ) requiring hemodialysis (zenith sCr: $18 \mathrm{mg} / \mathrm{dl}$ ). Viral myositis was suspected, but not confirmed in the muscle biopsy. Standard hemodialysis did not manage to effectively remove circulating myoglobin; so we decided to treat the patient with 5 sessions of CPFA, in combination with IV administration of methylprednisolone ( $50 \mathrm{mg}$ /day). Rhabdomyolysis rapidly resolved with prompt recovery of the renal function (sCr at discharge: $0.9 \mathrm{mg} / \mathrm{dl}$ ) and normalization of the inflammatory markers (fig. 1b). The clinical course is summarized in table 2. 
Table 1. Modification of clinical and blood test data before and after CPFA treatments in patient 1

\begin{tabular}{|c|c|c|c|c|c|c|c|}
\hline Day from $\mathrm{KT}, \mathrm{n}$ & - & - & 129 & 130 & 131 & 132 & 134 \\
\hline $\mathrm{sCr}, \mathrm{mg} / \mathrm{dl}$ & $0.6-1.2$ & $2.70 \pm 0.4^{*}$ & 4.80 & 6.57 & 3.81 & 2.66 & 3.06 \\
\hline $\mathrm{CRP}, \mathrm{mg} / \mathrm{l}$ & $<0.5$ & $0.01 \pm 0.007^{*}$ & 10.1 & 12.7 & 6.3 & 4.2 & 1.5 \\
\hline Procalcitonin, ng/ml & $<0.05$ & $0.01 \pm 0.002 *$ & 228.4 & 240.8 & 95.0 & 38.4 & 24.5 \\
\hline NLR & - & $9.7 \pm 1.2^{* *}$ & 21.0 & 29.9 & 34.2 & 17.7 & 12.5 \\
\hline Blood pressure, $\mathrm{mm} \mathrm{Hg}$ & - & $150 / 89^{* *}$ & $70 / 40$ & $90 / 60$ & $125 / 70$ & $120 / 70$ & $120 / 60$ \\
\hline $\mathrm{CI}, 1 / \mathrm{min} / \mathrm{m}^{2}$ & - & - & 2.96 & 3.24 & - & 3.94 & - \\
\hline SVRI, dynes*s $/ \mathrm{cm}^{5 *} \mathrm{~m}^{2}$ & - & - & 666 & 1,249 & - & 1,475 & - \\
\hline VIS & - & - & 12 & 6 & 6 & 0 & 0 \\
\hline Temperature, ${ }^{\circ} \mathrm{C}$ & - & $36.1 \pm 0.5^{* *}$ & 39.5 & 37.8 & 36.5 & 36.7 & 36.0 \\
\hline \multicolumn{2}{|l|}{$\mathrm{Qb}, \mathrm{ml} / \mathrm{min}$} & 150 & 160 & 140 & & & \\
\hline \multicolumn{2}{|l|}{ Total plasma, ml } & 8,100 & 7,200 & 7,400 & & & \\
\hline \multicolumn{2}{|c|}{ Plasma filtration flow rate, $\%$} & 15 & 15 & 15 & & & \\
\hline \multicolumn{2}{|c|}{ Total dose of heparin, IU } & 1,250 & 1,250 & 1,250 & & & \\
\hline \multicolumn{2}{|l|}{ Qinf, ml/min } & 25 & 25 & 25 & & & \\
\hline \multicolumn{2}{|c|}{ Ponderal weight loss, $\mathrm{ml} / \mathrm{kg}$} & 25 & 0 & 25 & & & \\
\hline
\end{tabular}

* Nadir and ** median value (from KT to adverse event).

$\mathrm{KT}=$ Kidney transplantation; ICU = intensive care unit; CRP = C-reactive protein; WBC = white blood cells; NLR = neutrophil-tolymphocyte ratio; $\mathrm{CI}=$ cardiac index; $\mathrm{SVRI}=$ systemic vascular resistance index; VIS = vasoactive-inotropic score; $\mathrm{Qb}=\mathrm{blood}$ flow; Qinf = blood reinfusion.

\section{Discussion}

CPFA has been seldom used in cases of solid organ transplantation recipients. To the best of our knowledge, there is only one study describing CPFA administration for the treatment of hyperbilirubinemia after liver transplantation [8]. No case reports in the setting of kidney transplantation are currently available.

CPFA has been extensively used to treat septic shock [2-5]. However, there is still no consensus, and the best strategy to stop the so-called 'septic cascade' has not been defined. The main benefit of using CPFA is in its ability to remove a wide spectrum of molecules, thus positively modulating the inflammatory systemic framework, in order to clear any imbalance between different types of sepsis mediators. In our experience, CPFA allowed quick clinical recovery in the patient and prompt reversal of the inflammatory imbalance. It is difficult to say if the reduction of procalcitonin values observed in the present case was correlated to its direct removal by CPFA or if it was caused by the clinical improvement of the patient. However, despite more than $20 \%$ of this molecule (approximately weighting $13 \mathrm{kDa}$ ) being commonly removed by adsorption techniques, we can suppose that its fast normalization is mainly connected with the resolution of the underlying inflammatory process [9].

No experience exists on the use of CPFA to treat severe hypermyoglobinemia. This is the first report of an episode of rhabdomyolysis that was successfully treated with CPFA. Main advantages of using CPFA as compared to standard hemodialysis filters are the following: (a) the ability to effectively remove myoglobin and (b) the chance to simultaneously manage acute kidney failure through continuous veno-venous hemofiltration. In the present case, complete resolution of both rhabdomyolysis and acute kidney injury were observed.

Several complex clinical conditions (i.e. septic shock or rhabdomyolysis) may be effectively treated using CPFA, especially in case of concomitant acute kidney failure. Despite the 2 cases herein reported, we cannot 
Table 2. Modification of clinical and blood test data before and after CPFA treatments in patient 2

\begin{tabular}{|c|c|c|c|c|c|c|c|c|c|}
\hline & $\begin{array}{l}\text { Normal } \\
\text { values }\end{array}$ & $\begin{array}{l}\text { Baseline } \\
\text { value }\end{array}$ & $\begin{array}{l}\text { Adverse } \\
\text { event }\end{array}$ & $\begin{array}{l}\text { Before } \\
\text { 1st CPFA }\end{array}$ & $\begin{array}{l}\text { Before } \\
\text { 2nd CPFA }\end{array}$ & $\begin{array}{l}\text { Before } \\
\text { 3rd CPFA }\end{array}$ & $\begin{array}{l}\text { Before } \\
\text { 4th CPFA }\end{array}$ & $\begin{array}{l}\text { Before } \\
\text { 5th CPFA }\end{array}$ & $\begin{array}{l}\text { At } \\
\text { discharge }\end{array}$ \\
\hline Day from KT & - & - & 5,597 & 5,604 & 5,605 & 5,608 & 5,609 & 5,614 & 5,622 \\
\hline $\mathrm{sCr}, \mathrm{mg} / \mathrm{dl}$ & $0.6-1.2$ & $0.90 \pm 0.3^{*}$ & 18.00 & 5.55 & 3.11 & 4.63 & 4.00 & 3.24 & 1.08 \\
\hline sGOT, IU/l & $0-40$ & $12 \pm 2^{*}$ & 488 & 612 & 560 & 221 & 152 & 41 & 20 \\
\hline sGPT, IU/l & $0-35$ & $9 \pm 3 *$ & 164 & 286 & 334 & 296 & 249 & 158 & 50 \\
\hline $\mathrm{CPK}, \mathrm{IU} / 1$ & $8-150$ & - & 21,201 & 39,145 & 20,560 & 8,826 & 4,932 & 589 & 96 \\
\hline LDH, IU/l & $56-194$ & - & 1,824 & 2,742 & 2,797 & 1,668 & - & 1,090 & 781 \\
\hline CRP, mg/l & $<0.5$ & $0.09 \pm 0.01^{*}$ & 5.25 & 7.99 & 4.99 & 1.61 & 1.25 & 0.33 & 0.11 \\
\hline \multicolumn{10}{|l|}{ Procalcitonin, } \\
\hline WBC, $\times 10^{3}$ & $4.8-10.8$ & $5.50 \pm 0.12^{* *}$ & 13.51 & 13.70 & 20.98 & 9.87 & 11.29 & 10.90 & 9.34 \\
\hline Temperature, ${ }^{\circ} \mathrm{C}$ & - & $36.2 \pm 0.5^{* *}$ & 37.4 & 36.5 & 36.0 & 36.0 & 35.7 & 36.0 & 36.0 \\
\hline Diuresis, $\mathrm{ml} / 24 \mathrm{~h}$ & - & $2,750 \pm 320^{* *}$ & 1,000 & 100 & 150 & 700 & 800 & 3,000 & 2,900 \\
\hline \multicolumn{3}{|c|}{ Specific data regarding CPFA procedures } & 1st CPFA & 2nd CPFA & 3rd CPFA & 4th CPFA & 5th CPFA & & \\
\hline \multicolumn{3}{|l|}{$\mathrm{Qb}, \mathrm{ml} / \mathrm{min}$} & 130 & 110 & 150 & 140 & 130 & & \\
\hline \multicolumn{3}{|l|}{ Total plasma, ml } & 6,500 & 3,300 & 7,400 & 8,000 & 5,400 & & \\
\hline \multicolumn{3}{|c|}{ Plasma filtration flow rate, $\%$} & 15 & 13 & 15 & 15 & 13 & & \\
\hline \multicolumn{3}{|c|}{ Total dose of heparin, IU } & 1,250 & 1,250 & 1,250 & 1,250 & 1,250 & & \\
\hline \multicolumn{3}{|c|}{ Qinf, $\mathrm{ml} / \mathrm{min}$} & 25 & 25 & 32 & 32 & 25 & & \\
\hline \multicolumn{3}{|c|}{ Ponderal weight loss, $\mathrm{ml} / \mathrm{kg}$} & 0 & 0 & 50 & 50 & 50 & & \\
\hline
\end{tabular}

* Nadir and ${ }^{* *}$ median value (from KT to adverse event).

$\mathrm{KT}=$ Kidney transplantation; sGOT = serum glutamate-oxaloacetate transaminase; sGPT = serum glutamate-pyruvate transaminase; $\mathrm{CPK}=$ creatine phosphokinase; $\mathrm{LDH}=$ lactate dehydrogenase; $\mathrm{CRP}=\mathrm{C}$-reactive protein; $\mathrm{WBC}=$ white blood cells; $\mathrm{NLR}$ = neutrophil-to-lymphocyte ratio; $\mathrm{Qb}=$ blood flow; Qinf = blood reinfusion.

provide strong evidences, but our experience suggests that CPFA can be safely offered to kidney transplant recipients when indicated. Pro-inflammatory substances like cytokines are commonly involved in several specific pathological processes observed in the transplant setting, such as delayed graft function, recurrence of primary renal disease and uremic hemolytic syndrome. Further studies are required in order to clarify the possible applications of CPFA in this scenario.

\section{Authorship}

Q.L. and F.P. designed the research; Q.L., V.D.P. and S.A. wrote the paper; Q.L., V.D.P., S.I., S.A. and K.C. collected the data; L.D.L., A.F. and F.P. participated in the critical evaluation of the paper.

\section{Funding}

No funding.

\section{Conflict of Interest}

S.A. is an employee of Bellco S.r.l.

\section{Disclosure Statement}

The authors declare that they have no conflicts of interest. 


\section{References}

1 Bellomo R, Tetta C, Ronco C: Coupled plasma filtration adsorption. Intensive Care Med 2003;29:1222-1228.

2 Berlot G, Agbedjro A, Tomasini A, Bianco F, Gerini U, Viviani M, et al: Effects of the volume of processed plasma on the outcome, arterial pressure and blood procalcitonin levels in patients with severe sepsis and septic shock treated with coupled plasma filtration and adsorption. Blood Purif 2014;37:146-151.

3 Livigni S, Bertolini G, Rossi C, Ferrari F, Giardino M, Pozzato M, et al: Efficacy of coupled plasma filtration adsorption (CPFA) in patients with septic shock: a multicenter randomised controlled clinical trial. BMJ Open 2014;4:e003536.
4 Nalesso F, Brendolan A, Zanella M, Ronco C: [Extracorporeal treatment of acute kidney injury during sepsis]. G Ital Nefrol 2012;29(suppl 56):S35-S40.

$5 \mathrm{Hu}$ D, Sun S, Zhu B, Mei Z, Wang L, Zhu S, et al: Effects of coupled plasma filtration adsorption on septic patients with multiple organ dysfunction syndrome. Ren Fail 2012;34:834839.

6 Harm S, Falkenhagen D, Hartmann J: Endotoxin adsorbents in extracorporeal blood purification: do they fulfill expectations? Int J Artif Organs 2014;37:222-232.
7 Cruz DN, Bagshaw SM: Does continuous renal replacement therapy have a role in the treatment of rhabdomyolysis complicated by acute kidney injury? Semin Dial 2011;24:417-420.

8 Maggi U, Nita G, Gatti S, Antonelli B, Paolo R, Como G, et al: Hyperbilirubinemia after liver transplantation: the role of coupled plasma filtration adsorption. Transplant Proc 2013;45:2715-2717.

9 Level C, Chauveau P, Guisset O, Cazin MC, Lasseur C, Gabinsky C, et al: Mass transfer, clearance and plasma concentration of procalcitonin during continuous venovenous hemofiltration in patients with septic shock and acute oliguric renal failure. Crit Care 2003; 7:R160-R166. 